\title{
Strategic Foresight in the One CGIAR: Gaps and Needs in Approaches and Capacity
}

\author{
Steven D. Prager ${ }^{1}$ and Keith Wiebe ${ }^{2}$
}

December 27, 2021

1. Alliance of Bioversity International and CIAT, Cali, Colombia

2. International Food Policy Research Institute, Washington DC, USA

This document is part of a series of working papers, produced as part of foresight-related research supported by the CGIAR Research Program on Policies, Institutions, and Markets (PIM), and intended to provide a focused, forward-looking perspective on key issues to support discussion on food, land, and water systems transformation.

This is a special edition of the series, based on the cumulative experiences of the CGIAR Foresight Community of Practice and recent One CGIAR Initiative development activities. This version is shared for discussion and comment. A final version will be made available at http://foresight.cgiar.org.

What is the issue?

Investment in strategic foresight research and practice is seen as a valuable activity across many different sectors. Businesses that use foresight to improve "future preparedness" demonstrate greater levels of profitability and growth (Rohrbeck \& Kum, 2018). Given both observed and anticipated impacts of climate change on agriculture and food systems, strategic foresight to guide policy and investment decisions has become commonplace and applied to a large cross section of key questions within the sector (Prager \& Wiebe, 2021).

While foresight approaches have, indeed, become commonplace and addressed a range of potential futures, there are still opportunities to improve in both research and practice. A recent set of reviews commissioned by the Independent Science for Development Council of the CGIAR suggests several critical gaps. They highlight the need to emphasize analysis of future agriculture systems in relation to poverty reduction, jobs, livelihoods and, especially, the need to consider these issues with a gender lens (ISDC, 2020, p3). Other pressing and future priorities highlighted by the ISDC include consideration of shocks and their impact on food prices, as well as the need for tradeoff analysis as an integral part of foresight to help identify links (both favorable and adverse) among different policies and investments (ISDC, 2020, p10).

Given that strategic foresight serves a multitude of roles, a range of foresight approaches are being developed both within and outside of the CGIAR to support similar big-picture questions, and that a range of methods are being used to "do" foresight, an important question emerges. What is the best way for foresight to grow and evolve with the CGIAR to maximally support CGIAR beneficiaries, the development investment community, and the CGIAR itself?

What research has been done?

A great deal of foresight work has already been developed in support of the CGIAR action areas. A substantial portion of this work has been supported and led by the Policies, Institutions, and Markets research program, with support from the Climate Change, Agriculture and Food Security research program and ongoing sponsorship and collaboration with USAID, the Bill and Melinda Gates Foundation, the Inter-American Development Bank, and the World Bank, among others. 
The collection of work by and in collaboration with the above partners has been developed in support of a range of key questions at the core of the CGIAR mission. Early work examined the effectiveness and potential return on investment of different sustainable intensification approaches in support of food security outcomes (Rosegrant et al., 2014). Related work in Latin America seized on the idea that heterogenous biophysical and socioeconomic landscapes benefit from different solutions depending on existing endowments and desired outcomes (Flachsbarth et al., 2015).

As foresight continued to be developed and deployed alongside CGIAR activities, the emphasis shifted somewhat toward understanding how to target different large-scale investment strategies. A USAID-commissioned study (Rosegrant et al., 2017) found that not only did different investment areas (e.g., irrigation and crop improvement) generate synergies (and tradeoffs) in relation to one another, but that these interactions also served to change the way in which agricultural systems interacted with the landscape and influenced both biodiversity and carbon sequestration and climate mitigation activities (Flachsbarth et al., 2015). Building on this, a collection of articles described in Prager and Wiebe (2021) and a study on the economic and nutrient impacts associated with targeted investments in productivity growth (Wiebe et al., 2021) further unpack the nuance of different investment strategies relative to potential goals, including desired food security, economic, environmental, and social outcomes.

\section{What has the research found?}

While the above studies illustrate the wide range of questions addressed by the CGIAR foresight community, they also shed light on some key areas where there remains opportunity to improve. In each of the studies, for example, there are different types of baseline analyses that serve as the counterfactual to different investment scenarios. Such baselines depend heavily on the assumptions in the underlying shared socioeconomic pathways (Hasegawa et al., 2015; O'Neill et al., 2017) and in the representative carbon concentration pathways (Van Vuuren et al., 2011). These assumptions substantially influence different quantitative model outcomes and should be carefully chosen (and updated) to assure that models keep pace with the changing realities we face at the global scale.

As shown by the previously highlighted study in LAC (Flachsbarth et al., 2015), the study supporting the multidonor initiative around Crops to End Hunger (Wiebe et al., 2021), and related work by Springmann et al. (2018), there is demonstrated demand for understanding future tradeoffs and trade spaces associated with different policy options across food, environment, and climate dimensions. At the same time, these studies also all use similar approaches to different ends; this shows the high level of nuance associated with these sorts of analyses and the need for ongoing refinement of approaches to structure and interpret foresight and tradeoff studies in a manner that is as transparent as possible.

Strategic foresight has advanced as major challenges in agriculture development have shifted away from a relatively narrow focus on food security. Agriculture research is increasing taking complex, multifaceted issues associated with the broader food system. For example, Godfray et al. (2016) demonstrate how maintaining liberal trade policy during significant losses of rice associated with fungal disease outbreaks can help mitigate potential declines in food security. Similarly, Wyckhuys et al., (2018) show how foresight can be used to increase understanding of the role of biological controls to soften cascading shocks associated with regional pest pressure on a globally traded commodity.

These examples illustrate the wide range of ways in which foresight has been integrated into strategic processes, both by the CGIAR and its partners. At the same time, there are many opportunities to continue refining the approaches and increasing the overall capacity of the CGIAR and partners to respond effectively, efficiently, and equitably to the challenges that lie ahead.

\section{What gaps deserve further work?}


Looking ahead, we see three principal areas for consideration in relation to the ongoing development of the CGIAR foresight capacity. These areas include metacapability, thematic and methodological issues, and emerging issues:

\section{Organizational Metacapability:}

The CGIAR system must co-evolve both in relation to the most pressing challenges as well as the needs of its national partners. Similarly, the foresight capacity within the system must evolve to orient quickly around key questions and core capability, while simultaneously anticipating and preparing for future needs of both the system and its partners. This continual reassessment and anticipatory capacity are known as metacapability (Furlong \& Johnson, 2003). One of the primary mechanisms to do this is enhanced collaboration and integration with a wide range of national partners, donor agencies, and stakeholders around the world. The engagement strategy in the new Foresight Initiative expressly incorporates this modality, spanning both internal and external partners.

Central to the enhanced partnership model is an extended set of communities of practice (CoPs). These CoPs will enhance knowledge management and information exchange among foresight practitioners and decision makers. Crucial to the knowledge management activities will be the newly launched CGIAR Foresight web portal (https://foresight.cgiar.org/). A core ambition of the new initiative is to also enhance measurement of the effectiveness of different foresight approaches. The Foresight Initiative will develop new approaches to instrument and measure how foresight works within different decision-making environments and use this information to help chart the course for future activities.

As highlighted by the ISDC (2020), foresight capability must become fully embedded within the entire CGIAR system. This implies both system-level foresight (i.e., foresight commissioned by and for the CGIAR system management) as well as system-wide foresight (i.e., foresight developed by and in collaboration with the full set of One CGIAR initiatives). The Foresight Initiative is a core collaborator in both processes, with a primary responsibility associated with addressing current and future partner needs and foresight capability, but foresightrelated work will be central to the activities of many other CGIAR initiatives as well.

In addition to metacapability at the organizational level, foresight readiness and agility also require ongoing investment in maintaining the basic foresight tools, skills, and core capacity needed to respond quickly to diverse policy challenges. These include routine updates of model parameters and data to ensure that forward-looking analyses are grounded in the best available current information.

\section{Expanding Thematic and Methodological Capability:}

Beyond maintaining up-to-date tools, new foresight capabilities are required to keep up with a rapidly evolving food system. The food system is vastly more interconnected than ever through telecoupling, complex capital flows, trade, dynamic social and institutional ties, and common resource use (Eakin et al., 2017). Inroads have been made (Wyckhuys et al., 2018), but further advances are required. Critical to advancing this capability will be improved understanding of consumer behavior. Consumer preferences are driving demand for both commodities and food products and these preferences themselves are evolving as a function of megatrends such as increasing wealth, urbanization, and market integration.

As markets become increasingly integrated, future supply chain disruptions are of greater concern. Anticipating the effect of different shocks, whether looking at the food security implications associated with Covid-19 effect on the supply chain (Laborde et al., 2021) or the adverse impacts of Covid-19 on incomes, employment, and food security (Arndt et al., 2020), will become increasingly critical with increased globalization. Couple this with increased climate variability, and increasing uncertainty around governance capacity to respond, and the necessity for foresight becomes astonishingly clear. Improved capability is needed to parse the implications of different shocks to increase resilience while considering the tradeoffs associated with different precautionary approaches.

In using foresight to better understand shocks such as those mentioned above, we are also better positioned to prepare for the risks associated with compound extreme events collocated in space and time (Zscheischler et al., 
2018). Larger-scale compound events such as "multiple breadbasket failures" (Gaupp et al., 2019) require similar inspection, especially considering the telecoupling and implications of trade already noted.

Trade brings with it a number of additional considerations that foresight analyses can help unpack. Increasing emphasis on producing the "the right crop in the right place" underscores the need to look at the local and regional capacity and tradeoffs around GHG mitigation and food security (Hasegawa et al., 2018) as well as considerations of labor and total factor productivity.

\section{Emerging Issues:}

While quantitative strategic foresight is a proven tool with which to explore alternative, plausible futures, there are several emerging areas that will likely drive new thinking on foresight. A marker of many these emerging issues is their fundamental multidimensional nature.

First, while some dimensions of climate change are reasonably well understood, the mid- to long-term implications on the intersecting agricultural, pest and disease, and biodiversity frontiers remain relatively unexplored. Farming system geographies are going to be continually changing alongside niches for pests and disease, and ecological niches for different plant, animal, and microbial species. All these issues have implications on the "right-crop-rightplace" question and must be collectively understood to improve overall resilience of the agriculture and food systems.

As mentioned in the previous section, consumer demand, trade, and global markets will also significantly drive the shape of future agricultural systems. Consumer demand will likely evolve much more rapidly than production systems and we must thus be capable of using foresight to examine the intersection of these fast and slow processes together. While globalization brings new products and opportunities, another important implication of the globalization of the food system and increasing linkages of lower income country participation in global markets is the exposure of these countries to distant shocks. Not only can global price fluctuations adversely impact the agricultural economy in the developing world, this globalization may also reduce local-level food sovereignty, creating new dependencies on the global marketplace while simultaneously reducing the capacity of local actors to grow and sell traditional varieties.

These issues are further complicated by large scale geopolitical drivers (e.g., emergence of the BRICS economies, realignment of western democracies, the Belt and Road Initiative, etc.). While we cannot necessarily model the influence of these changes on the agriculture development process, we can use foresight to better understand how new alignments might benefit from, be challenged by, or contribute to advancing the agriculture development agenda.

There is also emerging interest in agroecological and "nature positive" solutions. Foresight approaches have the potential to help support decision makers in striking the balance between nature positive solutions, agroecological approaches, sustainable intensification, and other intensification strategies. Diversity has long been a hallmark of resilient systems, and foresight approaches can help design diverse agriculture development strategies to address development priorities, consider environmental and climate goals, and account for social and cultural preferences.

Another emerging opportunity for the foresight community is to explore how new digital technologies are fundamentally changing the face of agriculture and food systems. From digital financial services to drones to advisory apps and market information systems, technology is changing the face of agriculture the world over. The implications of these technological changes are playing out over both the short and long term, with potentially positive productivity shocks, changing cropping decisions, or more efficient markets as the outcome. Current foresight approaches do not consider how technology may reduce friction in food systems or, alternatively, the implications of emerging digital divides.

Finally, there is increasing attention to themes at the intersection of climate security and food systems. From failing food systems as a driver of conflict, to conflict disrupting food systems and food supply, questions of climate 
security will become increasingly prevalent in some regions around the world. This, coupled with the previously described geopolitical changes suggest foresight approaches can be co-developed with the climate security community to better understand how climate related conflict may disrupt food systems or respond to targeted food systems interventions.

\section{Conclusions}

If the last decade of foresight activities in support of the CGIAR has taught us anything, it is the importance of systematically discussing and preparing for the future. Strategic foresight helps foster this dialog and creates a space for comparing ideas, the potential impacts of different policy and investment strategies, and the tradeoffs and synergies among different development trajectories. With some creativity, the inclusion of appropriate partners and stakeholders, and the development of new methods and approaches, foresight can help inform strategic decision making in One CGIAR and its partners to shape development pathways towards improved nutrition, livelihoods, equity, and climate and environmental outcomes.

\section{References Cited}

Arndt, C., Davies, R., Gabriel, S., Harris, L., Makrelov, K., Robinson, S., ... \& Anderson, L. (2020). Covid-19 lockdowns, income distribution, and food security: An analysis for South Africa. Global Food Security, 26, 100410.

Eakin, H., Rueda, X., \& Mahanti, A. (2017). Transforming governance in telecoupled food systems. Ecology and Society, 22(4).

Flachsbarth, I., Willaarts, B., Xie, H., Pitois, G., Mueller, N. D., Ringler, C., \& Garrido, A. (2015). The role of Latin America's land and water resources for global food security: environmental trade-offs of future food production pathways. PloS one, 10(1), e0116733.

Furlong, G. P., \& Johnson, L. (2003). Community of practice and metacapabilities. Knowledge Management Research \& Practice, 1(2), 102-112.

Gaupp, F., Hall, J., Mitchell, D., \& Dadson, S. (2019). Increasing risks of multiple breadbasket failure under 1.5 and 2 C global warming. Agricultural Systems, 175, 34-45.

Godfray, H. C. J., Mason-D'Croz, D., \& Robinson, S. (2016). Food system consequences of a fungal disease epidemic in a major crop. Philosophical Transactions of the Royal Society B: Biological Sciences, 371(1709), 20150467.

Hasegawa, T., Fujimori, S., Takahashi, K., \& Masui, T. (2015). Scenarios for the risk of hunger in the twenty-first century using Shared Socioeconomic Pathways. Environmental Research Letters, 10(1), 014010.

Hasegawa, T., Fujimori, S., Havlík, P., Valin, H., Bodirsky, B. L., Doelman, J. C., ... \& Witzke, P. (2018). Risk of increased food insecurity under stringent global climate change mitigation policy. Nature Climate Change, 8(8), 699-703.

ISDC (2020). Foresight and Trade-off Implications for One CGIAR. Independent Science for Development Council (ISDC).

Laborde, D., Martin, W., \& Vos, R. (2021). Impacts of COVID-19 on global poverty, food security, and diets: Insights from global model scenario analysis. Agricultural Economics. 
O’Neill, B.C., Kriegler, E., Ebi, K.L., Kemp-Benedict, E., Riahi, K., Rothman, D.S., van Ruijven, B.J., van Vuuren, D.P., Birkmann, J., Kok, K., Levy, M., Solecki, W. (2017), The roads ahead: Narratives for shared socioeconomic pathways describing world futures in the 21st century, Global Environmental Change 42: 169-180.

Prager, S.D.; Wiebe, K. (2021) Strategic foresight for agriculture: Past ghosts, present challenges, and future opportunities. Global Food Security 28: 100489 ISSN: 2211-9124

Rohrbeck, R., \& Kum, M. E. (2018). Corporate foresight and its impact on firm performance: A longitudinal analysis. Technological Forecasting and Social Change, 129, 105-116.

Rosegrant, M. W., Koo, J., Cenacchi, N., Ringler, C., Robertson, R. D., Fisher, M., ... \& Sabbagh, P. (2014). Food security in a world of natural resource scarcity: The role of agricultural technologies. Intl Food Policy Res Inst.

Rosegrant, M. W., Sulser, T. B., Mason-D’Croz, D., Cenacchi, N., Nin-Pratt, A., Dunston, S., ... \& Willaarts, B. (2017). Quantitative foresight modeling to inform the CGIAR research portfolio. Intl Food Policy Res Inst.

Springmann, M., Clark, M., Mason-D’Croz, D., Wiebe, K., Bodirsky, B. L., Lassaletta, L., ... \& Willett, W. (2018). Options for keeping the food system within environmental limits. Nature, 562(7728), 519-525.

Van Vuuren, D. P., Edmonds, J., Kainuma, M., Riahi, K., Thomson, A., Hibbard, K., ... \& Rose, S. K. (2011). The representative concentration pathways: an overview. Climatic change, 109(1), 5-31.

Wiebe, K., Sulser, T. B., Dunston, S., Rosegrant, M. W., Fuglie, K., Willenbockel, D., \& Nelson, G. C. (2021). Modeling impacts of faster productivity growth to inform the CGIAR initiative on Crops to End Hunger. PloS one, 16(4), e0249994.

Wyckhuys, K. A., Zhang, W., Prager, S. D., Kramer, D. B., Delaquis, E., Gonzalez, C. E., \& Van der Werf, W. (2018). Biological control of an invasive pest eases pressures on global commodity markets. Environmental Research Letters, 13(9), 094005.

Zscheischler, J., Westra, S., Van Den Hurk, B. J., Seneviratne, S. I., Ward, P. J., Pitman, A., ... \& Zhang, X. (2018). Future climate risk from compound events. Nature Climate Change, 8(6), 469-477. 